\title{
Measurements of dermal uptake of nicotine directly from air and clothing
}

Beko, G.; Morrison, G.; Weschler, Charles J.; Koch, H. M.; Paelmke, C.; Salthammer, Tunga; Schripp, T.; Toftum, Jørn; Clausen, G.

Published in:

Indoor Air Online

Link to article, DOI:

10.1111/ina.12327

Publication date:

2017

Document Version

Peer reviewed version

Link back to DTU Orbit

Citation (APA):

Beko, G., Morrison, G., Weschler, C. J., Koch, H. M., Paelmke, C., Salthammer, T., Schripp, T., Toftum, J., \& Clausen, G. (2017). Measurements of dermal uptake of nicotine directly from air and clothing. Indoor Air Online, 27(2), 427-433. https://doi.org/10.1111/ina.12327

\section{General rights}

Copyright and moral rights for the publications made accessible in the public portal are retained by the authors and/or other copyright owners and it is a condition of accessing publications that users recognise and abide by the legal requirements associated with these rights.

- Users may download and print one copy of any publication from the public portal for the purpose of private study or research.

- You may not further distribute the material or use it for any profit-making activity or commercial gain

- You may freely distribute the URL identifying the publication in the public portal

If you believe that this document breaches copyright please contact us providing details, and we will remove access to the work immediately and investigate your claim 
Received Date : 02-Jun-2016

Revised Date : 10-Aug-2016

Accepted Date : 20-Aug-2016

Article type : Original Article

\title{
Measurements of dermal uptake of nicotine directly from air and clothing
}

Gabriel Bekö ${ }^{1, *}$, Glenn Morrison ${ }^{2}$, Charles J. Weschler ${ }^{1,3}$, Holger M. Koch ${ }^{4}$, Claudia Pälmke ${ }^{4}$, Tunga Salthammer ${ }^{5}$, Tobias Schripp ${ }^{5}$, Jørn Toftum $^{1}$, Geo Clausen ${ }^{1}$

${ }^{1}$ Technical University of Denmark, Lyngby, Denmark,

${ }^{2}$ Missouri University of Science and Technology, Rolla, MO, USA,

${ }^{3}$ Environmental and Occupational Health Sciences Institute, Rutgers University, Piscataway, NJ, USA,

${ }^{4}$ Institute for Prevention and Occupational Medicine of the German Social Accident Insurance, Bochum, Germany,

${ }^{5}$ Fraunhofer WKI, Braunschweig, Germany

*gab@byg.dtu.dk

\begin{abstract}
In this preliminary study we have investigated if dermal uptake of nicotine directly from air or indirectly from clothing can be a meaningful exposure pathway. Two participants wearing only shorts and a third participant wearing clean cotton clothes were exposed to environmental tobacco smoke (ETS), generated by mechanically "smoking" cigarettes, for three hours in a chamber while breathing clean air from head-enveloping hoods. The average

This article has been accepted for publication and undergone full peer review but has not been through the copyediting, typesetting, pagination and proofreading process, which may lead to differences between this version and the Version of Record. Please cite this article as doi: 10.1111/ina.12327

This article is protected by copyright. All rights reserved.
\end{abstract}


nicotine concentration $\left(420 \mu \mathrm{g} / \mathrm{m}^{3}\right)$ was comparable to the highest levels reported for smoking sections of pubs. Urine samples were collected immediately before exposure and 60-h post exposure for bare-skinned participants. For the clothed participant, post-exposure urine samples were collected for 24-h. This participant then entered the chamber for another three-hour exposure wearing a hood and clothes, including a shirt that had been exposed for five days to elevated nicotine levels. The urine samples were analyzed for nicotine and two metabolites - cotinine and 3OH-cotinine. Peak urinary cotinine and $3 \mathrm{OH}$-cotinine concentrations for the bare-skinned participants were comparable to levels measured among nonsmokers in hospitality environments before smoking bans. The amount of dermally absorbed nicotine for each bare-skinned participant was conservatively estimated at $570 \mu \mathrm{g}$, but may have been larger. For the participant wearing clean clothes, uptake was $\sim 20 \mu \mathrm{g}$, and while wearing a shirt previously exposed to nicotine, uptake was $\sim 80 \mu \mathrm{g}$. This study demonstrates meaningful dermal uptake of nicotine directly from air or from nicotine-exposed clothes. The findings are especially relevant for children in homes with smoking or vaping.

\section{Keywords}

Exposure Pathway, Biomonitoring, Indoor Environment, E-cigarettes, Smoking, Vaping

\section{Practical Implications}

Significant dermal uptake of nicotine from either ETS or vaping may occur, and should be considered in exposure estimates, especially in environments with infants and children.

This article is protected by copyright. All rights reserved. 


\section{Introduction}

Recent studies suggest that dermal uptake of certain semivolatile organic compounds directly from air can be a significant exposure pathway (Weschler and Nazaroff, 2012, 2014). This has been experimentally confirmed for two phthalates (Weschler et al., 2015).

Dermal absorption of nicotine has long been known, including nicotine poisoning by dermal contact with pesticides or pure nicotine (Faulkner, 1933). Tobacco harvesters who neither smoked nor chewed tobacco have been found to have elevated levels of urinary cotinine, a nicotine metabolite, after handling green tobacco leaves (Gelbach et al, 1975). Transdermal patches are commonly used to deliver nicotine therapeutically (Pastore et al., 2015). Despite this knowledge, the air-to-skin-to blood pathway has been ignored in exposure assessments.

Nicotine is calculated to have a large overall permeability coefficient $\left(\mathrm{k}_{\mathrm{p}_{\_} \mathrm{g}}-\right.$ from air through skin to blood $-4.4 \mathrm{~m} / \mathrm{h}$, Weschler \& Nazaroff; 2014). For such a large estimated permeability coefficient, dermal uptake at steady-state could be greater than inhalation uptake for the freebase, gaseous form of nicotine. The Weschler and Nazaroff (2014) model assumes that nicotine remains un-ionized from air to blood, but this may not be the case at the surface of the skin. Nicotine is basic, with a pKa for the monoprotonated form of 8.0 (Benowitz et al., 2009). In an aqueous solution, a substantial fraction of nicotine will become protonated (ionized) at $\mathrm{pH}<8$. The $\mathrm{pH}$ of the skin surface can range from 4.5 to 6.5 , and the skin surface can contain a substantial amount of water (Fluhr et al., 2012). Lactic acid and amino acids can contribute to the buffering capacity (i.e., maintaining $\mathrm{pH}$ in a narrow range) of the surface of the skin (Levin and Maibach, 2008). Only the neutral form of nicotine readily passes through the stratum corneum; data from excised pig skin indicates monoprotonated nicotine passes through skin fifty times slower than neutral nicotine (Nair et al., 1997). Therefore, it is plausible that a substantial fraction of nicotine that transfers from air to the skin surface will become ionized, thereby slowing dermal uptake. On the other hand, skin surface lipids 
(primarily sebum with some lipids from the stratum corneum) are comprised primarily of triglycerides, squalene, cholesterol and other hydrophobic organic molecules that can absorb nicotine without contributing protons. In this form, nicotine would then readily pass through skin to the blood.

The dominant form of nicotine present at the skin surface is currently unknown. One can envision two different models of sweat and skin oils co-existing on skin surfaces. The first model is as a homogeneous surface film - the "acid mantle". In this case, a substantial amount of nicotine would ionize, resulting in much longer time to reach steady-state and a substantial reduction in nicotine transport through skin. The second model is as a heterogeneous surface film - islands of skin oil and islands of sweat. Here, nicotine is predicted to pass, un-ionized, through the islands of skin oil.

A preliminary study has been conducted to investigate if dermal uptake of nicotine directly from air or from clothing is substantial (i.e., comparable to inhalation intake). The results may also provide information regarding the dominant form of nicotine at the surface of the skin, indicating which of the above mental models better describes how water and skin-oils are distributed on skin surfaces.

\section{Materials/Methods}

Two experiments were performed; one investigating the dermal uptake of nicotine directly from air by two bare-skinned participants, and another one investigating the role of clothing in this uptake. Prior exposure of clothing has been shown to significantly enhance dermal uptake of phthalate esters (Morrison et al., 2016). In the bare-skin experiment, two healthy males, 35 and 67 years of age participated. They only wore shorts during exposure. A 49 years old male participated in the clothing experiment. There were two parts to the clothing experiment. In one, the participant wore a set of freshly laundered cotton clothes (undershirt, 
a pair of jeans, a long-sleeved tee-shirt, underwear, socks and gloves to minimize the exposed skin surface area). In the second, he wore an identical set of clean clothes, except for a shirt that had been exposed for five days to elevated nicotine levels (see below). During all exposure sessions, the participants breathed clean air through a hood. The breathing arrangement was identical to that described in Weschler et al. (2015). All participants were non-smokers and were not exposed to environmental tobacco smoke (ETS) during the days prior to the exposure and during the subsequent urine collection period.

A $55 \mathrm{~m}^{3}$ chamber was used for the exposure. To minimize sorption of nicotine on the chamber surfaces, the walls, floor and ceiling of the chamber were covered with thin polyethylene sheet (Figure S1). There was no mechanical ventilation and the window and door were closed during exposure. The air exchange rate estimated from the $\mathrm{CO}_{2}$ concentration build-up during exposure was $0.5 \mathrm{~h}^{-1}$. Nicotine was dosed in the chamber by a smoking machine continuously "smoking" by drawing air with a fan through cigarettes set in a manifold (Figure S2). Thus, the generated tobacco smoke was mainstream smoke. In order to avoid substantial sorption of nicotine to the surfaces during the actual human exposure, 88 cigarettes were "smoked" in the chamber over five days prior to the human exposures. During the time (3-h) that two bare-skinned participants and one freshly clothed participant were in the chamber, nicotine was dosed by continuously "smoking" three cigarettes at a time. During the chamber exposure of the participant wearing a nicotine-exposed shirt no cigarettes were smoked.

Nicotine in the chamber air was determined by collecting 0.5 to $1 \mathrm{~L}$ of air $(100 \mathrm{~mL} / \mathrm{min})$ on Tenax TA filled stainless-steel tubes before exposure and about 2 hours after the exposure (and cigarette "smoking") began in the first exposure experiment. The tubes were analyzed via thermal desorption gas chromatography/mass spectrometry (TD-GC/MS) according to DIN ISO 16000-6 (2012). The resulting nicotine concentration was $225 \mu \mathrm{g} / \mathrm{m}^{3}$ before 
exposure and $510 \mu \mathrm{g} / \mathrm{m}^{3}$ after steady-state was reached. These values represent both particlebound and gas-phase nicotine. We estimate that the average nicotine air concentration during exposure was $420 \mu \mathrm{g} / \mathrm{m}^{3}$ (see section S1 Air concentration of nicotine in Supporting Information for details). A field blank was also analyzed and its nicotine concentration was below the limit of detection $\left(<2 \mu \mathrm{g} / \mathrm{m}^{3}\right)$. The nicotine concentration was not measured in the hood. However, we performed spot measurements of $\mathrm{PM}_{2.5}$ within the hood during exposure, which indicated that there was no leak of chamber air into the hoods $\left(\mathrm{PM}_{2.5}\right.$ concentration $<1$ $\left.\mu \mathrm{g} / \mathrm{m}^{3}\right)$. The relationship between vapor-phase nicotine and respirable suspended particle $\left(\mathrm{PM}_{2.5}\right)$ mass emissions while smoking has been investigated by Leaderer and Hammond (1991). As a double check of our estimated average nicotine concentration, the concentration of $\mathrm{PM}_{2.5}$ was measured during the first exposure by a TSI DustTrak (TSI Inc., Shoreview, MN, USA). The results, summarized in section S1 Air concentration of nicotine in Supporting Information, support the nicotine levels measured using Tenax sorption tubes. Before entering the chamber, each participant collected one urine sample. Then two of the participants entered the chamber bare-skinned (wearing only shorts), while the third donned a fresh set of clothes. Three hours later the participants left the chamber and changed into their normal clothing. For the participants wearing only shorts, all urine was collected and weighed for the $60 \mathrm{~h}$ post-exposure. These samples were pooled for the first $12 \mathrm{~h}, 12-36 \mathrm{~h}$ and 36-60 h. For the clothed participant, urine samples were collected until the next morning ( $24 \mathrm{~h}$ postexposure). After collecting the $24 \mathrm{~h}$ sample, this participant entered the chamber for another three-hour exposure wearing a hood and a set of fresh clothes, except for a shirt that has been exposed to elevated nicotine levels. There were no cigarettes "smoked" during this exposure session. The concentration of nicotine in the air during these three hours was presumably substantially lower than in the clean clothes experiment and similar to that measured before exposure of the bare-skinned participants $\left(\sim 225 \mu \mathrm{g} / \mathrm{m}^{3}\right)$. The exposed shirt had been hanging 
in the chamber during the 5-days that it was conditioned by "smoking" 88 cigarettes. We estimate that the average concentration of nicotine in the air during the time the shirt was exposed was $>200 \mu \mathrm{g} / \mathrm{m}^{3}$.

The urine samples were analyzed for nicotine and two metabolites - cotinine and 3-hydroxycotinine (including their conjugates) via LC-MS with isotope dilution quantification. In short, urine was spiked with internal standard solutions of nicotine-d4, cotinine-d 3 and 3 hydroxycotinine-d3, enzymatically hydrolyzed with HP2 $\beta$-glucuronidase and chromatographically resolved in a two column assembly consisting of a Waters Oasis ${ }^{\circledR}$ HLB cartridge column $(2.1 \times 20 \mathrm{~mm} ; 25 \mu \mathrm{m})$ and a Hypercarb (Thermo Scientific) $(2.1 \times 100 \mathrm{~mm} ; 3 \mu \mathrm{m})$. Mass spectrometric detection and quantification was performed using a Waters Quattro Premier XE triple quadrupole mass spectrometer in positive ionization mode. The limits of quantification (LOQ) for nicotine, cotinine and 3-hydroxy-cotinine were $0.10,0.05$ and $0.12 \mu \mathrm{g} / \mathrm{L}$, respectively. It is noteworthy to mention that some other nicotine/nicotine metabolite methods determine these biomarkers without hydrolysis. Because half of the cotinine is excreted in its conjugated form (with other rations for nicotine and $3 \mathrm{OH}$-cotinine), those methods consequently produce lower biomarker concentrations than methods applying enzymatic hydrolyses. Creatinine was determined as a measure for urine dilution, but not needed for intake calculation, because full urine volume was collected. The mass of nicotine and each metabolite excreted was determined by multiplying the concentration by the urine volume; creatinine was measured but not used to normalize the results. The uptake of nicotine was calculated from the excreted amounts of nicotine and metabolites using the following molecular weights (g/mol): nicotine: 162, cotinine: 176, 3-hydroxy-cotinine: 192. Metabolic conversion factors, indicating the fraction of a dose of nicotine that is excreted as nicotine or a specific metabolite in urine have only been accurately established for humans with some degree of uncertainty. Therefore, we used several approaches and assumptions to 
extrapolate to nicotine uptake in our experiments. These are described in detail in the Results and Discussion section.

\section{Results and Discussion}

Nicotine concentration in air during exposure

The average nicotine concentration in the chamber air during exposure $\left(420 \mu \mathrm{g} / \mathrm{m}^{3}\right)$ was higher than concentrations routinely encountered in environments where smoking occurs. Air nicotine concentrations in German, Dutch and Swedish homes reached up to 14.3, 10.2 and $3.2 \mu \mathrm{g} / \mathrm{m}^{3}$, respectively (Gehring et al., 2006). Nicotine concentrations increased with questionnaire reported amounts of smoking. Median levels in homes where more than five cigarettes were smoked daily were $1.37 \mu \mathrm{g} / \mathrm{m}^{3}$ in Germany; $0.65 \mu \mathrm{g} / \mathrm{m}^{3}$ in the Netherlands and below the limit of detection in Sweden. The highest measured breathing-zone nicotine concentrations in Finnish pubs, restaurants and nightclubs were 39, 6.2 and $36 \mu \mathrm{g} / \mathrm{m}^{3}$, respectively (Johnsson et al., 2003). Median nicotine air concentrations reported for German and UK pubs and bars where smoking was permitted were an order of magnitude lower than in our chamber (Carrington et al., 2003; Bolte et al., 2008). However, our exposure concentration is comparable to the highest levels reported in these studies for smoking sections of UK pubs (Carrington et al., 2003) and in German discotheques (Bolte et al., 2008).

\section{Measured urine concentrations of nicotine and its metabolites}

Following ETS exposure, the bare-skinned participants excreted a substantial amount of nicotine and its metabolites (Figures 1, S4 and S5). The concentrations of analytes in all postexposure samples were considerably above those prior to exposure. Net excretions of nicotine and its metabolites for participants 1 and 2 were similar, although participant 1 excreted 
somewhat more nicotine, and somewhat less of the two measured metabolites. The concentration of nicotine increased faster in participant 1 than in participant 2, while participant 2 metabolized nicotine faster than participant 1 (Figures S4 and S5). Net excretion trends upwards through all samples (Figure 1) and the creatinine normalized concentrations of cotinine and $3 \mathrm{OH}$-cotinine are larger for the $36-60 \mathrm{~h}$ urine samples than for the $12-36 \mathrm{~h}$ samples (Figure S5), suggesting that absorption associated with the chamber exposure is not completely captured even after $60 \mathrm{~h}$. Although nicotine has an excretion half-life in the range of 100-150 min (based on intravenous injection; Hukkanen et al., 2005), it continues to be excreted even during the 36-60 h sample. This indicates that the skin acts as a long-term reservoir, delivering nicotine to the blood long after exposure.

Peak cotinine and $3 \mathrm{OH}$-cotinine concentrations in the urine of the bare-skinned participants were an order of magnitude higher than for non-smokers who avoid ETS exposure, comparable to levels measured among non-smokers in hospitality environments before smoking bans, and about half those measured for light smokers (Weiss et al., 2012). Cotinine levels were in fact around the generally accepted $50 \mathrm{ng} / \mathrm{ml}$ cut-point used to distinguish smokers from non-smokers (SRNT Subcomittee on Biochemical Verification, 2002). Mean urinary cotinine concentration among 23 non-smoking hospitality workers before smoking ban in the USA was $37.5 \mathrm{ng} / \mathrm{ml}$ (median $16.5 \mathrm{ng} / \mathrm{ml}$ ) (Jensen et al., 2010). Post-shift urinary nicotine and cotinine levels comparable to our data were found in employees working in semi-open-air bars and restaurants in Greece (Karabela et al., 2011). An earlier study in Finland by Husgafvel-Pursiainen et al. (1987) reported average urine cotinine levels of 56 $\mathrm{ng} / \mathrm{ml}$ for extensively exposed restaurant personnel. Concentrations above $30 \mathrm{ng} / \mathrm{ml}$ were measured in one third of the 128 eligible non-smoking bar workers in Toronto and Windsor, Ontario, Canada (Bondy et al., 2009). Somewhat lower geometric mean urinary cotinine 
concentrations $(3.8 \mathrm{ng} / \mathrm{ml})$ and $3 \mathrm{OH}$-cotinine concentrations $(18.8 \mathrm{ng} / \mathrm{ml})$ were reported for non-smokers exposed to ETS in hospitality environments (Johnsson et al., 2003). The authors found similar levels in the literature for non-smokers exposed to ETS at work and in homes. Maximum concentrations were however comparable to our peak concentrations.

It is noteworthy, that in a chamber study by Bernert et al. (2009), participants were exposed for four hours to a mean air nicotine concentration of $140 \mu \mathrm{g} / \mathrm{m}^{3}$ from sidestream cigarette smoke generated by a smoking machine. The urinary cotinine concentrations were between 24 and $35 \mathrm{ng} / \mathrm{ml}$. Hence, the nicotine concentration during exposure was about one third that in our study, yet the resulting cotinine levels were comparable to those measured for our bare-skinned participants. Presumably this reflects the fact that the participants were exposed to nicotine both dermally and via inhalation, and their exposure lasted one hour longer. In another controlled study, mean urinary cotinine levels were around $21.5 \mathrm{ng} / \mathrm{ml}$ for 16 nonsmoking adults immediately after a 1-hour secondhand tobacco smoke exposure at bar/restaurant levels, and it was around $30 \mathrm{ng} / \mathrm{ml}$ one and three hours later (Flouris et al., 2009).

Metabolite concentrations measured for the participant wearing an exposed shirt were similar to some of the lower levels (means/medians and below) summarized above for non-smoking children and adults in both homes and hospitality environments. The cotinine levels of this participant were higher than those measured in some of the non-smoking guests staying in smoking hotel rooms, which were significantly higher than for guests staying in non-smoking rooms (Matt et al., 2014). They are also comparable to concentrations measured in bar workers after the introduction of smoking ban. Although these levels are below or around what has been proposed as cutpoints to distinguish adult non-smokers exposed or not exposed 
to ETS (5 ng/ml and $10 \mathrm{ng} / \mathrm{ml}$; Haufroid \& Lison, 1998), they are above the level of 1.6 $\mathrm{ng} / \mathrm{ml}$ reported by unexposed non-smokers (Jarvis et al., 1984).

\section{Calculation of nicotine absorbed}

The minimum nicotine absorbed, based on the assumption that nicotine and its measured metabolites account for all nicotine absorbed, is $440 \mu \mathrm{g}$ for the bare-skinned participants ( 1 and 2). However, a better estimate of the minimum nicotine absorbed can be obtained by assuming that $90 \%$ of nicotine and its metabolites are excreted via urine and that the three metabolites and their conjugates constitute $85 \%$ of metabolites excreted in urine (Hukkanen et al., 2005). This results in an estimate of $570 \mu \mathrm{g}$ nicotine absorbed for both participants. It corresponds to $413 \mu \mathrm{g} / \mathrm{m}^{2}$ of body surface area for participant 1 (67 years old) and $368 \mu \mathrm{g} / \mathrm{m}^{2}$ for participant 2 (35 years old) (see section S2 Dermal uptake estimate in Supporting Information for body surface areas). Weschler et al. (2015) reported increasing dermal uptake from air of two phthalates with increasing age. It is also noteworthy that participant 1 showered late in the evening on the day of exposure, while in order to increase uptake, participant 2 decided to shower in the evening of the following day. Similar showering times may have resulted in a larger difference in normalized uptake between the two participants. However, the true effect of showering on nicotine ionization and absorption/storage in skin requires further attention.

The estimated total absorbed nicotine dose of $570 \mu \mathrm{g}$ for the bare skinned participants should be viewed as a lower limit. The concentration of nicotine and its metabolites had not returned to background levels in the last sample; therefore, some fraction of the nicotine absorbed during the exposure would have been excreted after $60 \mathrm{~h}$.

This article is protected by copyright. All rights reserved. 
The estimated minimum absorbed dose of nicotine for the bare-skinned participants in our study is equivalent to the nicotine dose from smoking $\sim 0.5-6$ cigarettes. This estimated equivalency is based on multiple studies. Using cigarettes containing ${ }^{14} \mathrm{C}$-labeled nicotine, Armitage et al. (1975) reported that the dose for a regular cigarette smoker would be about $25 \%$ of the nicotine in a cigarette, while that of a "non-smoker" would be only about $10 \%$. For the cigarette used in our study ( $0.9 \mathrm{mg}$ nicotine yield), the corresponding intake from smoking one cigarette would be between 90 and $225 \mu \mathrm{g}$. Others have reported nicotine intakes per cigarette around $1000 \mu \mathrm{g}$ or more, and found no correlation with the machine determined nicotine yield of the cigarette (Benowitz and Jacob, 1984; Feyerabend et al., 1985; Isaac and Rand, 1972).

Following ETS exposure, the participant wearing clean clothes excreted only a small amount of nicotine and its metabolites (Figures 1, S4 and S5). Nicotine absorbed was estimated to be about $20 \mu \mathrm{g}$. Clean clothes significantly reduced uptake relative to bare skin, but the excretion was also greater than background levels. This may reflect the small amount of exposed skin area at the wrists and neck for this participant. Substantially more uptake, 80 $\mu \mathrm{g}$, was observed when participant 3 wore a shirt previously exposed to both gas-phase and particle associated nicotine. Hence, some nicotine was transferred from clothing, through skin, to blood. The uptake from clothing was much less than that observed for bare-skinned participants, even though the shirt had been exposed to nicotine for five days. Lower observed uptake is probably because the average concentration of nicotine in the chamber air during the 5-day shirt exposure was lower than during the chamber exposure with participants. Further, the nicotine in the shirt probably had not come close to equilibration with the chamber air. Therefore, the air concentration of nicotine between skin and the exposed shirt was lower than that in the chamber air, but higher than that between skin and the clean shirt. Uptake would have been higher if the shirt had been exposed to elevated 
levels of gas-phase nicotine for a longer time, absorbing more nicotine. With sufficient exposure time, at the same gas-phase concentration as in the 3-h bare-skin and clean-clothes exposure, dermal uptake from clothing could exceed that for bare-skinned participants as was observed for phthalates in Morrison et al. (2016).

\section{Inhalation compared to dermal uptake}

Dermal uptake of nicotine is comparable to the estimated inhalation uptake if participants had not been wearing hoods. An inhalation uptake, $I U$, estimate is given by:

$$
I U=B R * C_{a i r} * f^{*} t
$$

where, $B R$ is the breathing rate, $C_{a i r}$ is the air concentration, $f$ is the fraction of inhaled nicotine that is absorbed and $t$ is the exposure time. A typical adult male breathes $\sim 0.7 \mathrm{~m}^{3} / \mathrm{h}$ (US EPA, 2011), and the average nicotine concentration in the chamber was $420 \mu \mathrm{g} / \mathrm{m}^{3}$. Armitage (1975) reports that for smokers $80-90 \%$ of nicotine in the inhaled air is absorbed (bioavailable), while for "nonsmokers" the value is 30-66\%. Iwase (1991) reports nicotine absorption of $60-80 \%$ for non-smoking women. We chose $f=0.7$ as a middle value from these studies of nonsmokers. For an exposure time of $3 \mathrm{~h}$, the calculated inhalation uptake mass is $620 \mu \mathrm{g}$, about $9 \%$ higher than the estimated dermal uptake of $570 \mu \mathrm{g}$. However, as noted above, the actual absorbed nicotine is likely higher than $570 \mu \mathrm{g}$, suggesting that dermal uptakes could even exceed inhalation uptake. Moreover, three hours of exposure is not sufficient to reach steady-state uptake for SVOCs such as nicotine (as was illustrated for phthalates in Gong et al. (2014)). A substantially longer exposure period would be required to reach steady-state absorption, at which point dermal uptake would be much larger. Indeed, the steady-state approach of Weschler and Nazaroff (2014) predicts an uptake of $8000 \mu \mathrm{g}$ at 
steady-state for a 3-h exposure at the nicotine concentration of this study (see calculations in SI). On the other hand, wearing clean clothing after exposure is anticipated to significantly reduce absorption due to transfer of nicotine from skin lipids to clothing (Weschler et al, 2015; Morrison et al., 2016). Given such transfer to clothing, the absorbed mass measured in this study is likely within a factor of five of the maximum anticipated absorption (neglecting ionization)

The concentration of $\mathrm{PM}_{2.5}$ during the first exposure was higher than in most environments with ETS. This will influence the partitioning of nicotine between the gas phase and airborne particles (Pankow, 2001). We estimate that under the average PM concentrations measured in the chamber during exposure, up to $30 \%$ of nicotine may have been present in airborne particles (see section S3. Estimated ratio of particle-bound and gas phase nicotine in chamber air in the Supporting Information). This is about one to two orders of magnitude higher than under typical conditions. The substantially lower fraction of nicotine in the gas phase may have led to a lower rate of dermal uptake directly from air compared to environments with typical PM levels, assuming the whole-air nicotine concentrations are equal for both scenarios. Dermal uptake from particles adhered to skin may have contributed to the total dermal uptake of nicotine. However, we estimate this contribution to be small given the gas phase and particle associated mass transfer coefficients that pertain to transport from the core of the room through the boundary layer adjacent to skin; the former is expected to be 50 to 500 times larger than the latter (Nazaroff et al., 1993; Weschler and Nazaroff, 2012).

This article is protected by copyright. All rights reserved. 


\section{Ionization}

Unfortunately, the uncertainty in our estimates of dermal uptake for the bare-skinned participants prevents us from quantitatively evaluating the extent of ionization of nicotine at the skin surface or determining which model of a skin surface film is appropriate. However, the minimum and larger values estimated for such uptake suggest that ionization is modest and does not strongly impede uptake of nicotine from air. That said, the long delivery of nicotine to blood $(>60 \mathrm{~h}$ ), suggests that substantial storage takes place on or in the skin. Nicotine storage on/in the skin could be amplified if it is present in both neutral and monoprotonated forms. Further experiments are necessary to address this issue, which is relevant not only for nicotine but for other SVOCs (e.g., 2,4-dichlorophenoxyacetic acid, pentachlorophenol, methamphetamine) that have large dermal permeability coefficients, but are either acidic or basic, and would be extensively ionized in aqueous solutions at $\mathrm{pH}$ values from 5 to 6 . The possibility of ionization also suggests that the results here should not be extrapolated beyond the specific conditions of the experiment, i.e. it is not necessarily the case that dermal dose scales linearly with air concentration. At a sufficiently high air concentration, ionization or acid-base molecular associations may become saturated in skin lipids as observed for methamphetamine (Parker and Morrison, 2016).

\section{E-cigarettes and thirdhand smoke}

The current results have implications in light of the growing popularity of e-cigarettes (German Cancer Research Center, 2013). Mainstream and secondhand e-cigarette aerosol contains a number of chemicals with potential health effects, including nicotine (Schripp et al., 2013; Goniewicz et al., 2014). People passively exposed to e-cigarette aerosol may absorb nicotine at levels comparable to passive smokers. Flouris et al. (2013) found that e-cigarettes and tobacco cigarettes generated similar effects on serum cotinine levels after passive 
smoking. Schober et al. (2014) measured substantial increase of air nicotine concentration from three people using e-cigarettes over a 2-hour period in a ventilated room. On the other hand, Czogala et al. (2014) concluded that secondhand exposure to airborne nicotine from ecigarettes is about $1 / 10^{\text {th }}$ of that from cigarette smoke. E-cigarette products and their use remain unregulated in many countries, leading to their use in otherwise smoke-free environments. The incidence of exposure associated with e-cigarettes among children younger than 6 years, as recorded by the US National Poison Data System, increased by 1500\% between 2012 and 2015 (Kamboj et al., 2016). The most common exposure route in these cases is ingestion; direct dermal contact also occurs, especially among young children (Forrester, 2015). Although dermal uptake from air is less of an acute threat than ingestion or contact with e-cigarette liquid, this pathway should be included in evaluating exposures to nicotine from e-cigarettes. Youth are rapidly adopting e-cigarettes (Grana et al., 2014), and the overall occurrence of vaping is increasing, in turn increasing the potential for dermal uptake of nicotine from air. This is of special concern in the case of infants and children, who may be exposed to nicotine from e-cigarettes even in ETS-free environments, including their homes.

Dermal uptake of nicotine from air and clothing may play a role also in environments where thirdhand smoke (THS) is a concern. THS consists of residual tobacco smoke pollutants that remain on surfaces after smoking and are re-emitted into the air or react with other compounds in the environment to produce secondary pollutants. Nicotine is one of the major constituents of THS. It has a strong tendency to sorb to surfaces, which can then become reservoirs of nicotine that can be re-emitted long after the cessation of active smoking (Singer et al., 2003, 2004). Nicotine often contaminates non-smoking environments where smoking formerly occurred. Moreover, THS is not constrained to indoor surfaces. It can be associated 
with the skin and clothes of both smokers and non-smokers who were exposed to secondhand smoke (Matt et al., 2011). Similar to e-cigarettes, transdermal uptake of nicotine from thirdhand smoke can be especially relevant for infants and children living in homes in which adults smoke, even if smoking occurs at times or in rooms when no children are present.

\section{Conclusions}

This preliminary study indicates that meaningful dermal uptake of nicotine directly from air can occur. Dermal uptake for bare-skinned participants was comparable to calculated inhalation uptake if the latter had occurred. The concentrations of nicotine and metabolites in the urine of participants were similar to non-smokers working in hospitality environments as well as light smokers. Clean clothes decreased the uptake compared to bare-skinned exposure. Wearing an ETS exposed shirt resulted in a roughly four times larger uptake than that with clean clothes. However, the resulting uptake was still substantially lower than for the bare-skinned participants.

The continued excretion of nicotine and its metabolites after $60 \mathrm{~h}$ indicates that skin acts as a reservoir, delivering nicotine to blood long after exposure. This delayed uptake may point to some ionization occurring at the skin's surface. However, the total nicotine uptake suggests that ionization does not substantially impede uptake.

In the near future we plan to conduct more detailed studies with a larger number of participants, more controlled concentrations using pure nicotine (instead of ETS), a longer exposure period, and urine collection over a longer time interval. Better understanding of dermal absorption of nicotine will lead to more complete assessments of nicotine exposure. This is especially important for infants and children in homes where smoking or vaping occurs.

This article is protected by copyright. All rights reserved. 


\section{Acknowledgements}

We would like to thank Nico Ziersen for building the smoking machine.

\section{References}

Armitage, A.K., Dollery, C.T., George, C.F., Houseman, H., Lewis, P.J. and Turner, D.M. (1975) Absorption and metabolism of nicotine from cigarettes. Brit. Med. J., 4, 313-316.

Benowitz, N.L. and Jacob, P. (1984) Daily intake of nicotine during cigarette smoking. Clin. Pharmacol. Ther., 35(4), 499-504.

Benowitz, N.L., Hukkanen, J. and Jacob, P. (2009) Nicotine chemistry, metabolism, kinetics and biomarkers. Handb. Exp. Pharmacol., 192, 29-60.

Bernert, J.T., Gordon, S.M., Jain, R.B., Brinkman, M.C., Sosnoff, C.S., Seyler, T.H., Xia, Y., McGuffey, J.E., Ashley, D.L., Pirkle, J.L. and Sampson, E.J. (2009) Increases in tobacco exposure biomarkers measured in nonsmokers exposed to sidestream cigarette smoke under controlled conditions. Biomarkers, 14, 2, 82-93.

Bolte, G., Heitmann, D., Kiranoglu, M., Schierl, R., Diemer, J., Koerner, W. and Fromme, H. (2008) Exposure to environmental tobacco smoke in German restaurants, pubs and discotheques. J Expo. Sci. Environ. Epidemiol., 18, 262-271.

Bondy, S.J., Zhang, B., Kreiger, N., Selby, P., Benowitz, N., Travis, H., Florescu, A., Greenspan, N.R. and Ferrence, R. (2009) Impact of an indoor smoking ban on bar workers' exposure to secondhand smoke. J. Occup. Environ. Med., 51, 612-619.

Carrington, J., Watson, A.F.R. and Gee, I.L. (2003) The effects of smoking status and ventilation on environmental tobacco smoke concentrations in public areas of UK pubs and bars. Atmos. Environ., 37, 3255-3266.

Czogala, J., Goniewicz, M.L., Fidelus, B., Zielinska-Danch, W., Travers, M.J. and Sobczak, A. (2014) Secondhand exposure to vapors from electronic cigarettes. Nicotine Tob. Res., 
$16,6,655-662$.

DIN ISO 16000-6. (2012) Indoor air - Part 6: Determination of volatile organic compounds in indoor and test chamber air by active sampling on Tenax $T A^{\circledR}$ sorbent, thermal desorption and gas chromatography using MS or MS-FID. Beuth.Verlag, Berlin.

Faulkner, J.M. (1933) Nicotine poisoning by absorption through the skin. J. Am. Med. Assoc., $100,1664-1665$.

Feyerabend, C., Ings, R.M.J. and Russell, M.A.H. (1985) Nicotine pharmacokinetics and its application to intake from smoking. Br. J. Clin. Pharmac., 19, 239-247.

Flouris, A.D., Metsios, G.S., Carrillo, A.E., Jamurtas, A.Z., Gourgoulianis, K., Kiropoulos, T., Tzatzarakis, M.N., Tsatsakis, A.M. and Koutedakis, Y. (2009) Acute and short-term effects of secondhand smoke on lung function and cytokine production. Am. J. Respir. Crit. Care Med., 179, 1029-1033.

Flouris, A.D., Chorti, M.S., Poulianiti, K.P., Jamurtas, A.Z., Kostikas, K., Tzatzarakis, M.N., Wallace Hayes, A., Tsatsakis, A.M. and Koutedakis, Y. (2013) Acute impact of active and passive electronic cigarette smoking on serum cotinine and lung function. Inhal. Toxicol., 25, 2, 91-101.

Fluhr, J.W., Darlenski, R., Lachmann, N., Baudouin, C., Msika, P., De Belilovski, C. and Hachem, J.-P. (2012) Infant epidermal skin physiology: adaptation after birth. Brit. J. Dermatol., 166, 483-490.

Forrester, M.B. (2015) Pediatric exposures to electronic cigarettes reported to Texas poison centers. J. Emerg. Med., 49, 2, 136-142.

Gehring, U., Leaderer, B.P., Heinrich, J., Oldenwening, M., Giovannangelo, M.E.C.A., Nordling, E., Merkel, G., Hoek, G., Bellander, T. and Brunekreef, B. (2006) Occup. Environ. Med., 63, 766-772

Gelbach, S.H., Williams, W.A., Perry, L.D., Freeman, J.I., Langone, J.J., Peta, L.V. and Van 
Vunakis, H. (1975) Nicotine absorption by workers harvesting green tobacco. Lancet, $305,478-480$.

German Cancer Research Center. (2013) Electronic cigarettes - an overview. Red Series Tobacco Prevention and Tobacco Control, Vol. 19. Heidelberg.

Gong, M., Zhang, Y. and Weschler, C.J. (2014) Predicting dermal absorption of gas-phase chemicals: transient model development, evaluation, and application. Indoor Air, 24, 292306.

Goniewicz, M.L., Knysak, J., Gawron, M., Kosmider, L., Sobczak, A., Kurek, J., Prokopowicz, A., Jablonska-Czapla, M., Rosik-Dulewska, C., Havel, C., Jacob, P. and Benowitz, N. (2014) Levels of selected carcinogens and toxicants in vapour from electronic cigarettes. Tob. Control, 23, 133-139.

Grana, R., Benowitz, N. and Glantz, S. (2014) E-Cigarettes, A scientific review. Circulation, $129,1972-1986$.

Haufroid, V. and Lison, D. (1998) Urinary cotinine as a tobacco smoke exposure index: A mini review. Int. Arch. Occup. Environ. Health, 71, 162-168.

Hukkanen, J., Jacob, P. III and Benowitz, N.L. (2005) Metabolism and Disposition Kinetics of Nicotine. Pharmacol. Rev. 57, 79-115.

Husgafvel-Pursiainen, K., Sorsa, M., Engström, K. and Einistö, P. (1987) Passive smoking at work: Biochemical and biological measures of exposure to environmental tobacco smoke. Int. Arch. Occup. Environ. Health, 59, 337-345.

Isaac, P.F. and Rand, M.J. (1972) Cigarette smoking and plasma levels of nicotine. Nature, 236, 308-310.

Iwase, A., Aiba, M., Kira, S. (1991) Respiratory nicotine absorption in non-smoking females during passive smoking. Int. Arch. Occup. Environ. Health, 63, 139-143.

Jarvis, M.J. and Russell, M.H. (1984) Measurement and estimation of smoke dosage to 
nonsmokers from environmental tobacco smoke. Eur. J. Respir. Dis., 133, 68 -75.

Jensen, J.A., Schillo, B.A., Moilanen, M.M., Lindgren, B.R., Murphy, S., Carmella, S., Hecht, S.S. and Hatsukami, D.K. (2010) Tobacco smoke exposure in nonsmoking hospitality workers before and after a state smoking ban. Cancer Epidemiol. Biomarkers Prev., 19, 1016-1021.

Johnsson, T., Tuomi, T., Hyvärinen, M., Svinhufvud, J., Rothberg, M. and Reijula, K. (2003) Occupational exposure of non-smoking restaurant personnel to environmental tobacco smoke in Finland. Am. J. Ind. Med., 43, 523-531.

Kamboj, A., Spiller, H.A., Casavant, M.J., Chounthirath, T., Smith, G.A. (2016) Pediatric exposure to e-cigarettes, nicotine, and tobacco products in the United States. Pediatrics, 137, 6, e20160041, DOI: 10.1542/peds.2016-0041.

Karabela, M., Vardavas, C.I., Tzatzarakis, M., Tsatsakis, A., Dockery, D., Connolly, G. and Behrakis, P. (2011) The Relationship between venue indoor air quality and urinary cotinine levels among semiopen-air cafe employees: What factors determine the level of exposure? J. Aerosol Med. Pulm. Drug Deliv., 24, 1, 35-41.

Leaderer, B.P. and Hammond, S.H. (1991) Evaluation of vapor-phase nicotine and respirable suspended particle mass as markers for environmental tobacco smoke. Environ. Sci. Technol., 25, 770-777.

Levin, J. and Maibach, H. (2008) Human skin buffering capacity: an overview. Skin Res. Technol., 14, 121-126.

Matt, G.E., Quintana, P.J.E., Fortmann, A.L., Zakarian, J.M., Galaviz, V.E., Chatfield, D.A., Hoh, E., Hovell, M.F. and Winston, C. (2014) Third-hand smoke and exposure in California hotels: non-smoking rooms fail to protect non-smoking hotel guests from tobacco smoke exposure. Tob. Control, 23, 264-272.

Matt, G.E., Quintana, P.J.E., Destaillats, H., Gundel, L.A., Sleiman, M., Singer, B.C., Jacob, 
P.III, Benowitz, N., Winickoff, J.P., Rehan, V., Talbot, P., Schick, S., Samet, J., Wang, Y., Hang, B., Martins-Green, M., Pankow, J.F., Hovell, M.F. (2011) Thirdhand tobacco smoke: Emerging evidence and arguments for a multidisciplinary research agenda. Environ. Health Perspect., 119, 1218-1226.

Morrison, G., Weschler, C.J., Bekö, G., Koch, H.M., Salthammer, T., Schripp, T., Toftum, J., Clausen, G. (2016) Role of clothing in both accelerating and impeding dermal absorption of airborne SVOCs. J. Expo. Sci. Env. Epid., 26, 113-118.

Nair, M.K., Chetty, D.J. and Chien, Y.W. (1997) Biomembrane Permeation of Nicotine: Mechanistic Studies with Porcine Mucosae and Skin. J. Pharm. Sci., 86, 257-262.

Nazaroff, W.W., Gadgil, A.J., and Weschler, C.J. (1993) Critique of the use of deposition velocity in modeling indoor air quality. In Modeling of Indoor Air Quality and Exposure, ASTM STP 1205, N.L. Nagda, Ed., American Society of Testing and Materials, Philadelphia, 81-104.

Pankow, J.F. (2001) Consideration of the role of gas/particle partitioning in the deposition of nicotine and other tobacco smoke compounds in the respiratory tract. Chem. Res. Toxicol., $14,11,1465-1481$.

Parker, K. and Morrison, G. (2016) Methamphetamine absorption by skin lipids: accumulated mass, partition coefficients, and the influence of fatty acids. Indoor Air, 26, 4, 634-641.

Pastore, M.N., Kalia, Y.N., Horstmann, M. and Roberts, M.S. (2015) Transdermal patches: history, development and pharmacology. Brit. J. Pharmacol., 172, 2179-2209.

Schober, W., Szendrei, K., Matzen, W., Osiander-Fuchs, H., Heitmann, D., Schettgen, T., Jorres, R.A. and Fromme, H. (2014) Use of electronic cigarettes (e-cigarettes) impairs indoor air quality and increases FeNO levels of e-cigarette consumers. Int. J. Hyg. Environ. Health, 217, 628-637.

Schripp, T., Markewitz, D., Uhde, E. and Salthammer T. (2013) Does e-cigarette 
consumption cause passive vaping? Indoor Air, 23, 25-31.

Singer, B.C., Hodgson, A.T., Nazaroff, WW. (2003) Gas-phase organics in environmental tobacco smoke. 2. Exposure-relevant emission factors and indirect exposure from habitual smoking. Atmos. Environ., 37, 5551-5561.

Singer, B.C., Revzan, K.L., Hotchi, T., Hodgson, A.T., Brown, N.J. (2004) Sorption of organic gases in a furnished room. Atmos. Environ., 38, 2483-2494.

SRNT Subcommittee on Biochemical Verification. (2002) Biochemical verification of tobacco use and cessation. Nicotine Tob. Res., 4, 149-159.

U.S. EPA (U.S. Environmental Protection Agency). (2011) Exposure Factors Handbook: 2011 Edition (Final). EPA/600/R-090/052F. Washington, DC: U.S EPA. Available: https://cfpub.epa.gov/ncea/risk/recordisplay.cfm?deid=236252 [accessed 20 May 2016].

Weiss, T., Koch, H.M., Wiethege, T. and Brüning, T. (2012) Passivrauch. In: Biomonitoring in Arbeitsmedizin und Umweltmedizin - Orientierungshilfe für Betrieb, Praxis und Klinik, Chapter 3.6, (Eds. Triebig, Drexler, Letzel, Nowak), Ecomed Medizin, Heidelberg, 279296.

Weschler, C.J. and Nazaroff, W.W. (2012) SVOC exposure indoors: fresh look at dermal pathways. Indoor Air, 22, 356-377.

Weschler, C.J. and Nazaroff, WW. (2014) Dermal uptake of organic vapors commonly found in indoor air. Environ. Sci. Technol., 48, 1230-1237.

Weschler, C.J., Bekö, G., Koch, H., Salthammer. T., Schripp, T., Toftum, J. and Clausen, G. (2015) Transdermal uptake of diethyl phthalate and di(n-butyl) phthalate directly from air: experimental verification. Environ. Health Persp., 123, 928-934.

This article is protected by copyright. All rights reserved. 


\section{Figure caption}

Figure 1. Net mass of excreted nicotine (NIC) and the two metabolites cotinine (COT) and 3hydroxy-cotinine (3-OH-COT). "Before exposure" is the mass excreted in the urination immediately prior to exposure.
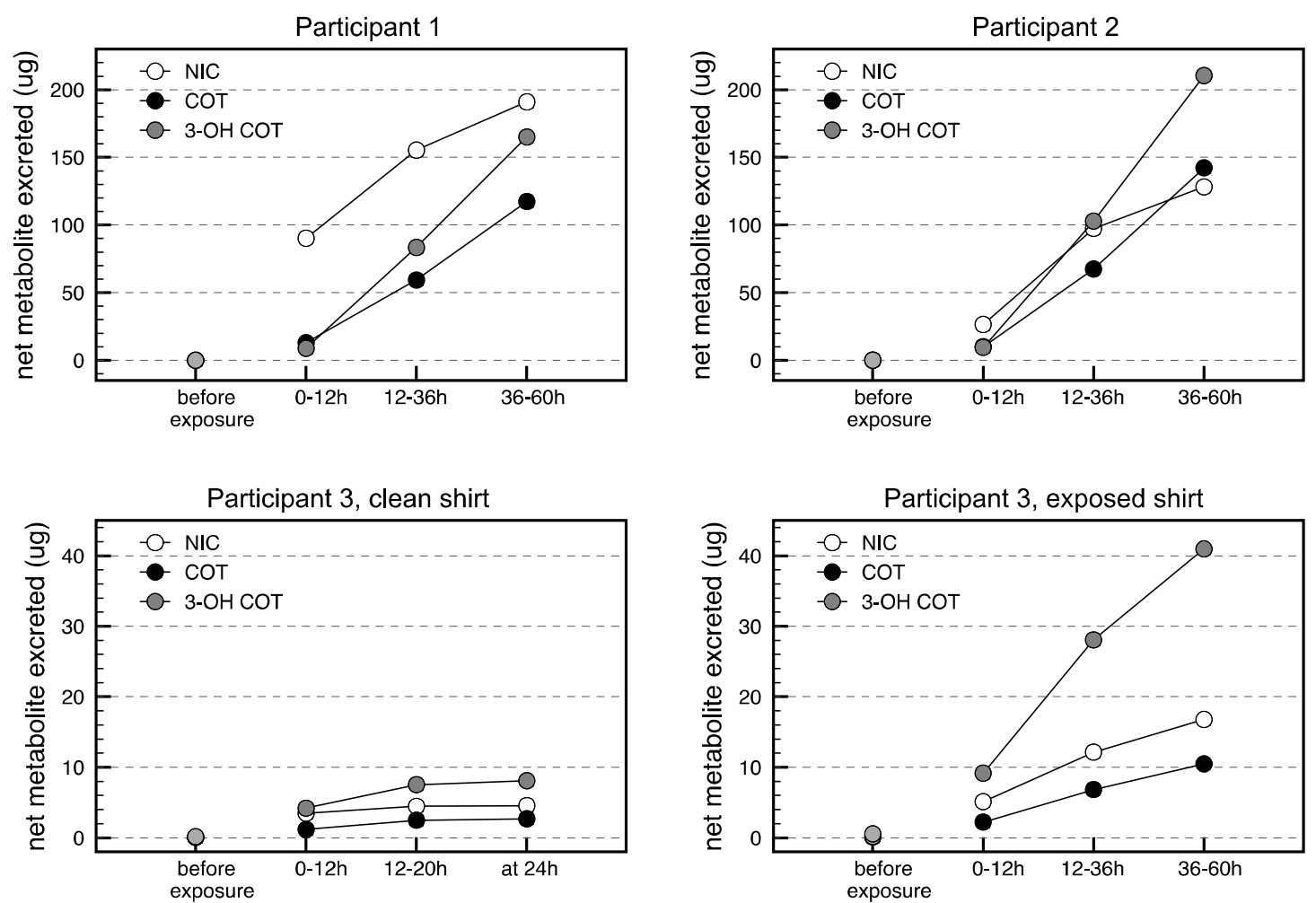

Figure 1

This article is protected by copyright. All rights reserved. 